\title{
A ORGANIZAÇÃO DA POLÍtTCA SOCIAL DO GOVERNO FERNANDO HENRIQUE
}

\author{
Sergio TiezzI
}

Resumo: O artigo trata da forma como o governo Fernando Henrique Cardoso organizou a área social, diante dos desafios impostos pelos indicadores e pela organização institucional do governo federal até 1994.

Palavras-chave: governo; políticas sociais; reforma do Estado.

\begin{abstract}
This article deals with the way the government Fernando Henrique Cardoso organized the social area while facing challenges imposed by the indicators and by the institutional organization of the federal government until 1994.

Key words: government; social politics; state reforms.
\end{abstract}

$\mathrm{O}$ governo Fernando Henrique Cardoso assumiu o país num momento particularmente grave no que diz respeito à situação social da população: não só era grande o contingente de brasileiros vivendo em situação de pobreza e indigência, como também as desigualdades de riqueza e de renda atingiram patamares imoralmente elevados. Pobreza e desigualdade, cujas raízes remontam ao passado histórico, mas cujas causas mais imediatas se encontravam nas limitações do processo de desenvolvimento com base na substituição de importações conduzido pelo Estado, na crise desse padrão de desenvolvimento, nas incertezas dos processos anteriores de ajuste econômico e nas conseqüências do processo de reestruturação econômica imposto pela globalização.

Avaliações feitas, na época, tanto por pesquisadores brasileiros como por analistas estrangeiros, que levam em conta definições e padrões comparativos internacionais, eram unânimes em considerar que o sistema brasileiro de proteção social era grande e complexo, se comparado com o de países com o mesmo nível de renda per capita e taxas semelhantes de urbanização.

Tendo-se estruturado com base na incorporação progressiva e desigual de diferentes corporações profissionais e segmentos sociais, bem como crescido, sobretudo, durante períodos de recrudescimento autoritário, o sistema de proteção social consolidado ao longo do tempo acabou se caracterizando por um esforço de gasto relativamente elevado (cerca de 18\% do PIB), grande centralização administrativa, escasso controle democrático, grandes ineficiências operacionais e por uma estrutura de benefícios com baixo conteúdo redistributivo. Além disso, uma rede complexa de interesses e de direitos adquiridos envolvendo políticos, funcionários, fornecedores e beneficiários privilegiados dificulta a reestruturação do sistema.

Dotar o país de um sistema eficiente e democrático de proteção social é tarefa complexa e difícil. Não se esgota nas responsabilidades - fundamentais - do governo federal e não se realiza de uma hora para outra. Sobretudo, desmontar desigualdades historicamente construídas não é tarefa de um governo, mas de gerações.

\section{A FORMULAÇÃO DA ESTRATÉGIA DE DESENVOLVIMENTO SOCIAL}

Nas condições de então (bastante adversas do ponto de vista tanto ideológico quanto econômico e fiscal) e para 
enfrentar os múltiplos desafios colocados, o governo Fernando Henrique entendeu ser necessário, por um lado, promover uma maior integração entre as várias políticas de governo, emprestando a todas elas marcada preocupação social, e, por outro, desenvolver com determinação quatro subconjuntos de ações ou políticas, indispensáveis para alcançar os objetivos desejados.

Em primeiro lugar, era preciso realizar um conjunto de ações que, não só por seus efeitos diretos, mas, sobretudo, por seus efeitos indiretos, constituem condições necessárias, embora não suficientes, para promover a melhoria do padrão de vida dos brasileiros. Neste sentido, era absolutamente indispensável assegurar as condições de estabilidade macroeconômica, realizar a reforma do Estado - aí compreendidas as reformas administrativa, fiscal e da previdência e outras medidas exigidas para a implantação de uma estratégia de desenvolvimento social - e retomar o crescimento econômico sob as novas condições de abertura da economia e elevada competição.

Em segundo lugar, era preciso concentrar todo esforço e atenção nos serviços sociais básicos de vocação universal: educação, saúde e previdência social. Os serviços prestados por estes setores, de oferta rotineira e continuada, constituem o núcleo de qualquer política social e compreendem mais de $90 \%$ do gasto público na área social. A reestruturação e a reforma profunda desses setores requeriam a eliminação de desperdícios, o aumento da eficiência desses setores, a promoção da descentralização, a universalização, sempre que necessário e legítima, de sua cobertura, a melhoria da qualidade e, sobretudo, a reestruturação dos benefícios e serviços para aumentar o seu impacto redistributivo.

A urgência e a gravidade da situação social brasileira exigiam programas e medidas cujo impacto ocorresse no curto prazo. Por isso, o governo Fernando Henrique se propôs, em terceiro lugar, a selecionar um conjunto de ações e programas considerados particularmente relevantes, para enfrentar pontos de estrangulamento mais dramáticos (como a reforma agrária), para acelerar o processo de reforma e reestruturação de serviços sociais (como a melhoria do ensino fundamental) e para proporcionar atenção a grupos sociais que requeriam ação imediata e inadiável (a redução da mortalidade na infância, a renda mínima para idosos e deficientes de baixa renda e a erradicação do trabalho infantil, por exemplo). Essas ações e programas mereceram atenção prioritária e esforço concentrado de articulação, financiamento, gerenciamento e avaliação.
Entretanto, era necessário experimentar um novo mecanismo para coordenar as políticas voltadas para o enfrentamento de situações agudas de fome e de miséria, de situações sociais de emergência e de calamidade pública. Isso foi feito por meio do Programa Comunidade Solidária, cuja função básica deveria ser aprimorar os programas federais direcionados para regiões mais vulnerabilizadas, bem como coordenar e focalizar suas ações com base em critérios técnicos de necessidade e eficácia, diminuindo os riscos de pulverização e clientelismo e promovendo uma adequada articulação entre os diferentes níveis de governo. Essa tarefa se desdobrou posteriormente na adoção do Índice de Desenvolvimento Humano - IDH da ONU como critério de alocação de recursos e na criação de programas de transferência direta de renda para as famílias mais pobres, como a Bolsa Escola e o Bolsa Alimentação, eliminando burocracias para a chegada de recursos financeiros aos beneficiários.

Em quarto lugar, mas da maior importância para o modelo de política social que o governo Fernando Henrique adotou, foi a criação do Conselho da Comunidade Solidária, constituído pelos ministros das áreas econômica e social do governo e por pessoas representativas da sociedade civil, cuja função essencial além de acompanhar a ação social da administração federal, propondo medidas e sugerindo modificações de rumo - consistia em articular formas de parceria entre o governo e a sociedade civil e suas diversas organizações no enfrentamento da questão social, inovando e experimentando. A partir deste Conselho, foram desenvolvidas parcerias entre programas governamentais e setores da sociedade civil (empresas, universidades, sindicatos, ONGs, igrejas, etc.) para atividades de política social junto a segmentos e regiões indicados por suas necessidades e carências. Foram criados e desenvolvidos, a partir de então, os programas Alfabetização Solidária, Universidade Solidária, Artesanato Solidário e Capacitação Solidária.

Um novo papel era atribuído ao Estado. Não deveria mais ser o grande produtor de bens e de serviços, mas sim usar seu poder de sinalização e de regulamentação e sua capacidade de investir para tornar viáveis empreendimentos de outras instituições que se considerem desejáveis: esferas subnacionais de governo (Estados e municípios), empresas privadas e entidades da sociedade civil e das comunidades. 


\section{DESCENTRALIZAÇÃO NA ÁREA SOCIAL}

Ao mesmo tempo, a profunda descentralização de ações da área social permitiu o fortalecimento do nível local para a tomada de decisões - e não apenas da aplicação dos recursos - e formulações de acordo com as necessidades de cada localidade. A descentralização foi uma forma eficiente de gerir o gasto público. A proximidade com o usuário permite, com maior segurança, que as diversas esferas de governo participem da oferta dos serviços, evitando possíveis desequilíbrios entre oferta e procura, causados por desconhecimento das demandas dos usuários.

Uma ordenação desse processo de descentralização exigiu, entre outras medidas:

- evitar a duplicidade de ações das esferas de governo, extinguindo órgãos federais e procurando eliminar programações orçamentárias, em áreas nas quais a presença da União tornou-se supérflua ou inadequada. Um exemplo foi a extinção da FAE - Fundação de Amparo à Escola e a descentralização dos recursos para compra da merenda escolar;

- regularizar e dar transparência às transferências voluntárias, notadamente no que diz respeito aos setores de educação e saúde, condicionando-as à melhoria do esforço próprio de Estados e municípios e à efetiva assunção dos encargos e responsabilidades que, antes da redistribuição de receitas, competiam à União. A criação de um Fundo específico de garantia do financiamento do ensino fundamental (Fundef) e uma Emenda Constitucional de garantia de aplicação de recursos na saúde por todos os níveis de governo são exemplos.

Além da reforma funcional do Estado, por meio da qual se redefiniram as funções do setor público, redistribuíramse as funções entre os diferentes níveis de governo e aumentou-se a participação social nos processos decisórios, foi levado a cabo, como condição necessária, o gerenciamento mais adequado dos programas sociais, para a execução de um conjunto eficiente de políticas de proteção social.

Os serviços sociais, no país, tinham um elevado grau de ineficiência e ineficácia e um baixo impacto redistributivo, bem como exclusões na universalidade do acesso. A instabilidade dos recursos, presente nas três esferas de governo, alimentava a ineficiência do sistema, comprometia a continuidade dos programas, prejudicava a prestação de serviços e chegava a inibir uma maior agilidade no processo de descentralização. A frágil articula- ção entre os órgãos encarregados dos programas e a excessiva fragmentação e superposição de ações dificultavam elevar o grau de eficácia e eficiência dos recursos alocados.

Mudar as formas de organização e gerenciamento na área social, incentivando a descentralização, a parceria com a sociedade civil e a transparência, constitui linhas de ação com um certo consenso e estratégia no país há alguns anos. Agregou-se a isso a necessidade de focalização de determinados programas com potencial de impacto importante sobre a pobreza, com vistas a um efetivo atendimento das camadas mais pobres da população.

Trata-se de um processo que exigiu o comprometimento de todos os atores que atuam na área (governo federal, Estados, municípios e sociedade civil), pois era uma tarefa impossível de ser executada por um só dos participantes. Além disso, dada a heterogeneidade que caracteriza o Brasil e a multiplicidade de atores envolvidos, esperavase que o processo se desenvolvesse de forma desigual entre as diferentes regiões e áreas.

\section{ESFERAS DE ARTICULAÇÃO E COORDENAÇÃO: UMA NOVA FORMA DE ORGANIZAÇÃO DO GOVERNO}

À chegada ao governo, antecedeu um longo trabalho de planejamento estratégico que redundou em uma agenda criada a partir do programa de governo (Mãos à Obra, Brasil) apresentado à sociedade brasileira nas eleições de 1994.

No caso da política social, foi elaborado um documento, coordenado pelo assessor especial do presidente da República, Vilmar Faria, com colaboração de todos os ministros da área social, para nortear a ação do conjunto do governo. O documento "Uma Estratégia de Desenvolvimento Social" teve por objetivo sistematizar as diretrizes básicas do governo Fernando Henrique Cardoso para a área social e apresentar, de forma sucinta, suas principais políticas e programas.

Não é necessário insistir na importância de mecanismos de articulação e de coordenação de políticas em qualquer área. Essa importância aumenta diante de alguns fatores, entre os quais: tamanho e heterogeneidade do país; complexidade e diferenciação institucional do aparelho estatal ou público responsável pelas políticas; volume e complexidade dos recursos financeiros envolvidos; forma de organização estatal; modalidade prevalescente de oferta de serviços públicos (estatal centralizada, estatal 
descentralizada, pública descentralizada, parceria com organizações não-governamentais, etc.). Esses fatores incidem sobre a definição dos principais problemas de articulação e coordenação de políticas e, portanto, sobre as possíveis soluções.

Por sua vez, a articulação e a coordenação da área social têm suas especificidades e uma forma de gerenciamento muito particular. A metodologia de gerenciar uma obra ou projeto de execução física, que tem variáveis bem conhecidas, quantificáveis e locáveis no tempo, é muito diferente daquela utilizada para gerenciar um empreendimento de natureza mais mobilizadora de posturas e ações de pessoas, como são os projetos sociais.

A responsabilidade de execução dos diferentes componentes da política social brasileira se distribui pela União, Estados e Municípios. No plano federal, fica a cargo de cerca de dez ministérios, sendo que cinco - Previdência Social, Saúde, Educação, Desenvolvimento Agrário e Trabalho e Emprego, que são grandes estruturas burocráticas, com tradição e influência - movimentam volumosos recursos e são responsáveis pelo financiamento e controle normativo de políticas e programas que, em seu conjunto, atendem a mais de 150 milhões de pessoas.

A implementação dos mais de cinqüenta programas que formam o conjunto de medidas de proteção social envolve complexas relações intergovernamentais no plano federal e outras, não menos complexas, com os demais entes da federação. Além disso, boa parte dos programas possui ainda conselhos de participação social nas deliberações públicas, com representação paritária de governo e sociedade civil organizada. Com freqüência, esses conselhos se desdobram em conselhos federais, estaduais e municipais.

No caso brasileiro, as estruturas encarregadas de desempenhar essas funções estiveram na Presidência da República, com mandato explícito, apoio e participação direta do presidente. Cabia ao ministro-chefe da Casa Civil articular e coordenar todas as ações administrativas do governo federal. As funções da Casa Civil passavam por viabilizar a construção de consensos, construir a integração e o entendimento, articular programas e ações, contribuir para identificação dos temas fundamentais para cada Câmara, trabalhar junto às equipes dos ministérios para "fazer acontecer", acompanhar as ações de maior relevância do governo e contribuir para identificação de problemas e proposição de soluções.

Nesse sentido, iniciativa importante para melhorar o desempenho da administração federal foi a criação de
Câmaras Setoriais, reunindo ministros por área temática ou macroproblemas, sob o comando operacional da Casa Civil, com a presença permanente dos Ministérios do Planejamento e Orçamento e da Fazenda, em todas as Câmaras, de forma a facilitar - quando não garantir - os recursos financeiros e orçamentários às decisões tomadas.

A estas Câmaras atribuiu-se a função de construir consensos para as políticas de governo, "facilitando" as decisões do governo como tal. Além disso, possibilitou a todos os ministros e Ministérios clareza maior da agenda prioritária de governo.

As organizações de governo têm uma atuação muito fragmentada (feudos), muitas vezes com prioridades distintas e mesmo contraditórias, e não havia nenhum instrumento de gestão que coordenasse as prioridades da agenda de governo. As Câmaras foram uma tentativa de resolver as contradições e conflitos existentes dentro do governo, que permitissem sair de lá com posições assumidas por todos os ministros de Estado.

Uma de suas funções era qualificar as ações segundo o andamento, possibilitando acender as "luzes de alerta" no caso de um programa não ir bem e premiar aqueles com resultados expressivos.

Muitas Câmaras tinham um secretário executivo, responsável por dar curso às decisões tomadas. Todas contavam ainda com um Comitê Executivo, formado pelos secretários executivos dos Ministérios envolvidos - os segundos da hierarquia dos Ministérios -, cuja função básica era a orientação para resolver problemas e implementação operacional das políticas, programas e projetos. Os problemas de integração, articulação e coordenação operacional que não tinham solução nessa etapa, voltavam à instância ministerial da Câmara.

A princípio, essas reuniões eram organizadas com uma composição fixa, mas, com a experiência, concluiu-se que deveriam ser variáveis, organizadas em função dos problemas de articulação e coordenação a serem tratados.

A organização do governo em Câmaras Setoriais implicou a definição de programas prioritários - aqueles que efetivamente deixariam uma marca de transformação para o país e para o governo - e o início do desenvolvimento de um sistema de monitoramento e avaliação permanentes dos programas sociais prioritários. Esse monitoramento, feito pela equipe da Casa Civil, significava se colocar na posição de co-responsável pelo sucesso ou fracasso de programas prioritários, uma vez que a Casa Civil é uma instância com muito mais facilidade de resolver gargalos dos programas que envolvem outros setores do governo. 
O primeiro instrumento utilizado para esta finalidade foi o Sistema de Acompanhamento das Ações Relevantes, desdobrado e aperfeiçoado posteriormente para sistemas mais elaborados, sofisticados e extensivos, como o Brasil em Ação, coordenado pelo Ministério do Planejamento, Orçamento e Gestão. Essa metodologia, no segundo mandato do presidente Fernando Henrique Cardoso, serviu de base para a elaboração do Plano Plurianual de Investimentos (PPA) 1999-2002.

Os objetivos do Sistema de Acompanhamento das Ações Relevantes eram dotar o governo, e especialmente o presidente da República, de informações objetivas e fundamentadas sobre o conjunto das principais ações em execução, propiciar mecanismos de acompanhamento do que era particularmente relevante pelos ministérios executores e pela Presidência da República e ampliar os instrumentos para gerenciamento e pleno desempenho dos programas prioritários.

\section{QUADRO 1}

Importância da Identificação de Ações Relevantes

- Facilidade em iluminar o conjunto de ações do governo

- Possibilidade de prestação de contas transparente e eficaz

- Reconhecimento, por parte da Presidência e dos ministros, do que é prioritário para o governo

- Identificação dos recursos e da atenção necessária à plena execução das prioridades

O resultados da ação das Câmaras Setoriais de Governo foram desiguais. Entre as bem-sucedidas, estão a Câmara de Política Econômica - que se reuniu semanalmente até o fim do governo, quase sempre com a presença do presidente da República, a Câmara de Infra-Estrutura e a Câmara de Política Social. Em 2001, com a crise energética pela qual passou o país, foi criada uma Câmara de Gestão da Crise de Energia para administrar o racionamento de energia necessário para evitar apagões e tomar as medidas para evitar a ocorrência de novos problemas dessa natureza no futuro.

O sucesso dessas iniciativas variou de programa para programa e deveu-se, igualmente, mais a fatores de natureza político-administrativa do que àqueles de centralização burocrática. Entre eles, cabe mencionar: capacidade técnica e de gestão dos secretários-executivos setoriais; continuidade administrativa; convergência de perspectiva no que se refere às orientações da estratégia de desenvolvimento social; sustentação política recebida pelos ministérios; e legitimidade conseguida junto às máquinas administrativas. Há um fator subjetivo com enorme influência na resultante final das políticas: a construção de uma relação de confiança entre a Casa Civil e os Ministérios. Quando o Ministério entendia a Casa Civil efetivamente como parceira, ou seja, pessoas com quem se podia contar, tendia a ter uma sinergia maior nas ações. Quando os Ministérios encaravam o papel da Casa Civil como de supervisão indesejada ao andamento das ações, havia maior dificuldade de os programas saírem do lugar. ${ }^{1}$

\section{A CÂMARA DE POLÍTICA SOCIAL}

Como visto, o governo selecionou um conjunto de programas e ações que mereciam atenção especial e prioritária, como parte de sua estratégia de desenvolvimento social, por sua importância e impacto imediato nas condições de vida de amplos setores da população, especialmente das camadas mais pobres.

A Câmara de Política Social da Casa Civil da Presidência da República, criada como instância superior de coordenação da política social do governo, por meio do Decreto $\mathrm{n}^{\mathrm{o}} 1.918$, de 13 de agosto de $1996,{ }^{2}$ teria a responsabilidade de assegurar as condições necessárias para a execução desses programas, em relação tanto à garantia do fluxo de financiamento e à qualidade do gerenciamento, quanto ao acompanhamento, avaliação e revisão das ações propostas, quando o resultado for considerado insatisfatório.

A ação social dos diversos Ministérios foi agrupada com base em quatro critérios principais:

- programas voltados a alterar, imediatamente, o modo rotineiro de funcionamento de serviços sociais básicos, como é o caso da valorização do ensino fundamental;

- programas que enfrentem situações graves e emergenciais de segmentos sociais em situação de extrema dificuldade, como a população empobrecida do campo e os idosos e deficientes físicos;

- ações específicas destinadas a reduzir ou eliminar a fome, como os programas de alimentação e nutrição;

- programas que envolvam tarefas urgentes ditadas pelo novo padrão de crescimento econômico e sua exigência de se aumentar a empregabilidade de importantes segmentos da força de trabalho.

Em resumo, impunha-se como um grande desafio para a política social brasileira a profunda reestruturação desse sistema, visando: 
- descentralizar a execução;

- elevar a participação e o controle públicos;

- racionalizar gastos;

- aumentar a eficiência alocativa;

- eliminar desperdícios;

- melhorar a qualidade dos serviços prestados;

- ampliar a cobertura universalizando os serviços e, sobretudo, aumentar o seu impacto redistributivo.

Em artigo recentemente publicado, o então chefe da assessoria especial do presidente da República, Vilmar Faria (2003), coloca sua visão da configuração de governo na área social: "A experiência brasileira recente não consagra como uma alternativa necessária, ou mesmo desejável, a criação de uma 'autoridade social', entendida como uma superestrutura burocrática, sob o controle de um ministro, que reúne poderes operacionais em algumas ou em todas as áreas setoriais da política social. Uma iniciativa desse tipo seria politicamente inviável e operacionalmente ineficaz. Diferentemente do que ocorre na área econômica, onde os mecanismos de operação são relativamente poucos e altamente eficientes - o orçamento, a taxa de juros, o câmbio, o controle de receitas, entre outros - na área social estes instrumentos são muito mais numerosos e de eficiência mais restrita. Além do mais, boa parte do corpo técnico operacional se encontra em ministérios setoriais". Centralizar a ação social não seria, portanto, eficaz. "Ao contrário, a experiência brasileira aponta noutra direção: reformar e fortalecer as estruturas setoriais do ponto de vista funcional e técnico, dotá-las de força, prestígio e poder político e desenvolver mecanismos e não estruturas burocráticas de articulação e coordenação" (Faria, 2003).

Essa forma de funcionamento permitiu o desenvolvimento de iniciativas muito bem-sucedidas para dar conta da estratégia de desenvolvimento social do governo brasileiro.

A primeira, denominado Projeto Alvorada, consistiu num conjunto de doze programas elaborados no âmbito de diversos Ministérios, com o objetivo de dotar os municípios brasileiros que possuem índice de desenvolvimento humano baixo (inferior a 0,500) de infra-estrutura básica, necessária para as atividades de desenvolvimento social e humano. Os programas são executados setorialmente e o papel dessa iniciativa é fazer com que estes programas setoriais cheguem, prioritariamente, a essas regiões e que ali sejam implementados coordenadamente pelas autoridades e sociedade local. Outro aprendizado desse processo foi a percepção de que é nos municípios onde ocorre uma verdadeira integração de políticas sociais setoriais.
A segunda iniciativa, denominada Comunidade Ativa, teve cobertura e alcance mais reduzidos e estava voltada para apoiar iniciativas comunitárias de desenvolvimento local integrado (sob o lema: não dar o peixe, ensinar a pescar). Foram escolhidos municípios cujas comunidades tenham revelado alguma capacidade de mobilização, organização e ação, com o objetivo de encontrar novas formas para dinamizar e desenvolver suas potencialidades. Com base na organização e na capacitação microempresarial (empreendedorismo) dessas comunidades, são identificadas carências e demandas, e o governo federal procura mobilizar seus programas para apoiar iniciativas de desenvolvimento local.

Uma terceira iniciativa foi a criação de um Programa de Apoio à Gestão Social, no âmbito da própria Presidência da República, para trazer à agenda dos programas instrumentos de gestão social novos: a importância de sistemas de informações gerenciais atualizados e amigáveis; avaliação de resultados para correção de rumos; capacitação em gestão social e suas especificidades. A transformação da gestão no governo era vista como essencial para que as mudanças estabelecidas no campo formal - reformas constitucionais, nova legislação, novas estruturas e novo aparelho regulatório - pudessem se tornar mais permanentes. Se não houver avanços na mudança das posturas gerenciais - o que significa reestruturar a forma de administrar, redefinindo, em trabalho conjunto, qual o objetivo, a missão, para que existe, quem são e o que demandam os clientes de fato de cada posto de serviço, estabelecendo metas e revendo os processos e estruturas de cada órgão -, o que fica é precário e referencialmente formal para que se transforme de verdade no novo Estado que a sociedade deseja. Não há, entretanto, ajuste ou equilíbrio fiscal que se sustente sem uma profunda revisão gerencial. Os gastos continuarão a ser desproporcionais àquilo que a sociedade precisa e está disposta a financiar, exatamente porque não se sabe precisamente as características dessa demanda. Esse tipo de mudança é um processo lento, de difícil administração e que, por isso mesmo, deveria ser iniciado logo, prosseguir com paciência e persistência e ser emanado a partir do núcleo central de governo, até mesmo para ter influência sobre esferas subnacionais de governo.

Uma quarta iniciativa foi a extinção por decreto da Legião Brasileira de Assistência - LBA, instituição historicamente constituída, foco de clientelismo, ineficiência e corrupção, símbolo da maneira "velha" de fazer política social. 
Outra iniciativa foi a articulação para a implantação do Programa de Erradicação do Trabalho Infantil - Peti, hoje reconhecido internacionalmente, que implicou colocar na mesma mesa, compartilhando os mesmos objetivos, o Ministério da Previdência e Assistência Social, o Ministério do Trabalho e o Ministério da Justiça, todos responsáveis por algum tipo de ação para possibilitar o bom funcionamento do programa. O Peti terminou por ser um dos casos de sucesso do governo Fernando Henrique Cardoso.

Outro aspecto da coordenação das políticas sociais referiu-se à continuidade e à eficácia administrativa dos programas sociais. Segundo Vilmar Faria (2003), “Do ponto de vista orçamentário, tratou-se de criar mecanismos que protejam os principais programas sociais das variações cíclicas e dos cortes de gastos que as exigências do equilíbrio fiscal podem, periodicamente, impor". Aqui, duas iniciativas foram tomadas.

A primeira, conhecida como Programa Avança Brasil, consiste na escolha de um subconjunto de programas que têm prioridade orçamentária e para os quais foram desenvolvidos mecanismos especiais de gerenciamento, acompanhamento e avaliação.

A segunda, conhecida como Rede de Proteção Social, ocorre no contexto das negociações levadas a cabo pelo Brasil em 1998, junto ao FMI, ao Banco Mundial e ao BID, com o objetivo de obter apoio desses organismos para proteger a economia brasileira dos ataques especulativos e das crises financeiras que periodicamente ameaçam os países emergentes. Como parte dos compromissos assumidos pelo país, junto com as metas de controle da inflação e redução do déficit público, foram assumidos compromissos e metas físicas e financeiras para 22 programas considerados essenciais para proteger diversos segmentos da população mais carente (como manutenção dos recursos para pagamento do seguro-desemprego, da renda mensal para idosos, financiamento do ensino fundamental).

Aqui, novamente, prevaleceu a criação de mecanismos dotados de operacionalidade, legitimidade, capacidade técnica e respaldo político mais do que a criação de estruturas burocráticas centralizadas.

Por último, foi extremamente importante assinalar a importância da formação de uma equipe social politicamente coesa, identificada com a estratégia de desenvolvimento social proposta pelo chefe do Executivo e tecnicamente competente, para o êxito dos mecanismos de coordenação e articulação.

\section{ALGUNS RESULTADOS}

À par de existirem grandes desafios a serem enfrentados pelo Brasil nas próximas décadas, houve uma evolução constante e sustentável dos indicadores sociais no campo dos serviços sociais de responsabilidade pública, especialmente em saúde e educação.

O analfabetismo caiu para $12,8 \%$ em 2001 e a taxa de escolaridade atingiu $97 \%$ das crianças na faixa de 7 a 14 anos. Das crianças mais pobres, $92 \%$ estão hoje na escola contra $75 \%$ em 1992. A mortalidade infantil caiu para 28,4 por mil nascidos vivos contra 39,6 em 1994. Na área da reforma agrária, 465 mil famílias foram assentadas em oito anos, o que representa mais do que o dobro do total de famílias assentadas entre 1964 e 1994 . Os esforços para erradicar o trabalho infantil tiraram 400 mil crianças e adolescentes de atividades penosas ou degradantes. A proporção de pobres no Brasil se reduziu de $43,9 \%$ para $31,9 \%$ e os indigentes, de $19,5 \%$ para $14,5 \%$. A parcela de renda resultante das transferências de serviços governamentais - entre eles aposentadorias e programas de transferência direta de renda - subiu de $10,34 \%$ para $14,66 \%$, em claro sinal da importância do papel do Estado no oferecimento das garantias sociais para a população. É o funcionamento da chamada rede de proteção social. Mesmo a desigualdade social, estagnada por mais de trinta anos, embora permaneça elevada, sofreu uma pequena redução e o Brasil melhora a cada ano sua posição no ranking de Desenvolvimento Humano, elaborado pelas Nações Unidas.

De 1991 a 2000, a qualidade de vida medida pelo Índice de Desenvolvimento Humano Municipal - IDH-M melhorou em 99,9\% dos municípios do país. As cidades com menos de 50 mil habitantes foram as que mais elevaram a qualidade de vida da população. A pequena melhora no rendimento e a dificuldade de desconcentrar renda impediram que o avanço - impulsionado principalmente pela educação, com o aumento do número de matrículas no ensino básico - fosse ainda maior. Das três dimensões que compõem o índice de qualidade de vida, a renda foi a que menos subiu no Brasil: apenas $6,1 \%$, enquanto a educação cresceu $13,9 \%$ e a longevidade aumentou $9,8 \%$.

Esses avanços foram obtidos mesmo num quadro de baixo crescimento econômico. Se ao longo do século XX, o aumento da riqueza não se traduziu em desenvolvimento social e igualdade, nos anos 90 houve melhorias sociais mesmo com redução do ritmo de crescimento econômico. 


\section{NOTAS}

1. Na Casa Civil tomou-se a decisão de que a sua equipe deveria ir aos Ministérios para reuniões e debates em vez de convocar as equipes dos Ministérios para o Palácio do Planalto, onde funciona a Casa Civil. Parece trivial, mas não é. Teve efeitos diretos na criação de uma relação de confiança entre as equipes e na formação de uma equipe de governo.

2. O atual governo manteve a Câmara de Política Social, mas a reformulou por meio do Decreto $n^{\circ} 4.714$, de 30 de maio de 2003.

\section{REFERÊNCIAS BIBLIOGRÁFICAS}

BRASIL. PRESIDÊNCIA DA REPÚBLICA. Uma estratégia de desenvolvimento social. Brasília: 1996.

BRESSER PEREIRA, L.C.; GRAU, N. (Orgs.). O público não estatal na reforma do Estado. Rio de Janeiro: Fundação Getúlio Vargas, 1999.

BOBBIO, N. Direita e esquerda: razões e significados de uma distinção política. São Paulo: Editora Unesp, 1994.

CASTELLS, M. A Era da informação: economia, sociedade e cultura. 2. ed. São Paulo: Paz e Terra, v.1, 1999.

COSTA, V.L. (Org.). Descentralização da educação: novas formas de coordenação e financiamento. São Paulo: Cortez, 1999.
FARIA, V.F. Reformas institucionais e coordenação governamental: o caso da política de proteção social no Brasil. In: TEIXEIRA, M. (Org.). Universidade e governo: professores da Unicamp no período FHC. São Paulo: 2003. p.15-48.

MELO, M.A. (Org.). Reforma do Estado e mudança institucional no Brasil. Recife: Fundação Joaquim Nabuco, 1999.

MINISTÉRIO DO PLANEJAMENTO, ORÇAMENTO E GESTÃO. Fórum Global: Estado Democrático e Governança no Século XXI. Anais... Brasília, 2000.

NEGRI, B. O financiamento da educação no Brasil. Brasília: INEP, 1996.

NOGUEIRA, M.A. Un Estado para la sociedad civil. Revista del CLAD: Reforma y Democracia, Caracas, n.14, p.95-118, 1999.

NÚCLEO DE ESTUDOS DE POLÍTICAS PÚBLICAS/UNICAMP. Avaliação qualitativa de programas sociais prioritários: síntese dos principais resultados da pesquisa de campo. Campinas: Unicamp, 1999.

SCHWARTZ, G. Além da estabilização: do Plano Real à reconstrução da economia política brasileira. Tempo Social: Revista de Sociologia da USP, São Paulo, v.11, 2000.

Sergio Tiezzi: Assessor da Secretaria de Assistência e Desenvolvimento Social do Estado de São Paulo. Foi assessor da área social na Casa Civil da Presidência da República e do ministro da Educação nos governos de Fernando Henrique Cardoso. 